Utah State University

DigitalCommons@USU

$5-1980$

\title{
The Effects of Tri-O-Tolyl Phosphate (TOTP) on the Immune System of Mice
}

Craig R. Brinkerhoff

Utah State University

Follow this and additional works at: https://digitalcommons.usu.edu/etd

Part of the Toxicology Commons

\section{Recommended Citation}

Brinkerhoff, Craig R., "The Effects of Tri-O-Tolyl Phosphate (TOTP) on the Immune System of Mice" (1980). All Graduate Theses and Dissertations. 4301.

https://digitalcommons.usu.edu/etd/4301

This Thesis is brought to you for free and open access by the Graduate Studies at DigitalCommons@USU. It has been accepted for inclusion in All Graduate Theses and Dissertations by an authorized administrator of DigitalCommons@USU. For more information, please contact digitalcommons@usu.edu.

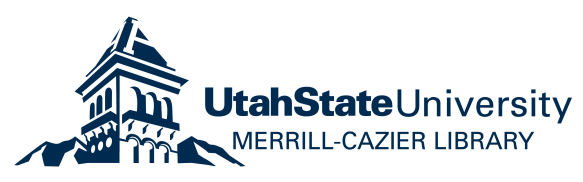


THE EFFECTS OF TRI-O-TOLYL PHOSPHATE (TOTP) ON THE IMMUNE SYSTEM OF MICE

by

Craig R. Brinkerhoff

A thesis submitted in partial fulfillment

of the requirements for the degree

of

MASTER OF SCIENCE

in

Toxicology

Approved:

UTAH STATE UNIVERSITY

Logan, Utah

1980 


\section{ACKNOWLEDGMENTS}

I would like to thank at this time the many people who have made the completion of this project possible. My sincere thanks go to Dr. R. P. Sharma who provided the funds and facilities as well as offered suggestions and helpful instructions. Dr. Sharma was a great help throughout the project and in writing this thesis. Drs. P. B. Carter and S. J. Kleinschuster critically reviewed the manuscript, and offered many suggestions and helpful hints throughout the project. Denis R. Bourcier aided in the laboratory work and compilation of the data. Stephen A. Christensen helped in killing the animals and collecting the needed organs. Thanks to Michael E. Paskett for assistance in using the Coulter counter. William Bracken, Craig Farr, and Charles Aldous were all very helpful and their friendship appreciated. 
TABLE OF CONTENTS

Page

ACKNOWLEDGMENTS. . . . . . . . . . . . . . . . ii

LIST OF TABLES ...................... . . . iv

LIST OF FIGURES. . . . . . . . . . . . . . . . . . v v

ABSTRACT . . . . . . . . . . . . . . . . . vi vi

INTRODUCTION . . . . . . . . . . . . . . . . 1

REVIEW OF LITERATURE . . . . . . . . . . . . . . . 4

Toxic Effects.................... . 4

Animal Studies. .............. . . 5

Pathologic Studies. .............. 6

Epidemiology. . ................. . . 7

Case Studies................. . . . 8

Related Phosphate Case Studies. . . . . . . . . . 9

Immunologic Studies Involving TOTP. . . . . . . . . 10

The Immune System. . . . . . . . . . . . . . 12

Immunotoxicology and Environmental Chemicals. . . . . 13

MATERIALS AND METHODS. . . . . . . . . . . . . . 15

Animal Treatment. . . . ......... . 15

Design of Experiment. .. . . . . . . . . . . 16

Splenic Lymphocyte Cultures . . . . . . . . . 18

Plaque Formation. . . . . . . . . . . . . . 19

Delayed Hypersensitivity: Radioisotpe Food-Pad Assay . . 20

Quantitative Immunoelectrophoresis. . . . . . . . 21

Statistical Manipulation and Data Presentation. . . . . 22

RESULTS. . . . . . . . . . . . . . . . 23

Splenic Lymphocyte Cultures . . . . . . . . . . 23

Plaque Formation. . . . . . . . . . . . 29

Delayed Hypersensitivity. . . . . . . . . . . 29

Quantiative Immunoelectrophoresis and Hematology. . . . 29

DISCUSSION . . . . . . . . . . . . . 32

SUMMARY. . . . . . . . . . . . . . . . 35

LITERATURE CITED . . . . . . . . . . . . . . . 36

VITA . . . . . . . . . . . . . . . 40 


\section{LIST OF TABLES}

Table

Page

1. Organ and body weights of mice treated with different dose levels of TOTP and TMTP. . . . . . . .

2. Lymphocyte proliferation response of mice exposed to TOTP and TMTP. . . . . . . . . . . . .

3. Plaque forming cells and delayed hypersensitivity food count ratio. . . . . . . . . . . . . .

4. Quantitative immunoloelectrophoresis of mouse serum immunoglobulins... . . . . . . . . 30

5. Whole blood erythrocyte and Iymphocyte counts . . . . 31 


\section{LIST OF FIGURES}

Figure

Page

1. Relative proliferation index of splenic

lymphocyte cultures to PHA. . . . . . . . . .

2. Relative proliferation index of splenic

1ymphocyte cultures to PWM. . . . . . . . . . . .

3. Relative proliferation index of splenic

lymphocyte cultures to LPS. . . . . . . . . . 
ABSTRACT

The Effects of Tri-0-Tolyl Phosphate (TOTP) on the Immune System of Mice

by

Craig R. Brinkerhoff, Master of Science

Utah State University, 1980

Major Professor: Dr. R. P. Sharma

Department: Toxicology

TOTP is a prevalent industrial and environmental contaminant which has been shown to be a neurotoxic agent. This study was undertaken to investigate the effects of this compound on the immune system. Several techniques were employed to test the humoral as well as cellular effects. Male Swiss Webster mice were administered by gastric gavage with three doses of TOTP (5, 50, and $500 \mathrm{mg} / \mathrm{kg}$ ) and one dose TMTP ( $50 \mathrm{mg} / \mathrm{kg}$ ) in corn oj.1 once a week for 13 weeks. Control animals were given corn oil alone.

Lymphocyte transformation was determined on cultures of splenic cells obtained from animals sacrified at $1,4,8$, and 13 weeks. Relative Proliferation Index (RPI) and Stimulation Index (SI) was calculated for phytohemnagglutinin (PHA), pokeweed (PWM), and lipopolysaccharide (LPS) mitogen treated cultures. Proliferation was measured by uptake of radioisotope labeled thymidine. 
Plaque formation as well as delayed hypersensitivity was evaluated at all dose levels after 4 weeks of treatment. Humoral effects were determined utilizing quantitative (Rocket) immunoe1ectropheresis. Serum was compared with control serum for IgA, IgG, and IgM fractions.

TOTP was found to cause slight suppression in proliferation of splenic 1ymphocytes at 8 and 13 weeks although this suppression was non-specific and not dose related. No effects were seen on body and organ weights. Plaque forming cells and delayed hypersensitivity were not affected either by dose or time of treatment. Immunoglobulin fractions tested were similarly not affected by time or dosage. These findings suggest that neither TOTP nor TMTP exhibit immunotoxic effects at levels used. 


\section{INTRODUCTION}

Tri-o-tolyl phosphate (TOTP or TOCP) is of interest because it is an adulterant of flavor extracts and cooking oils and a contaminant of tricresyl phosphate which is widely used as industrial oils, plasticizers, lubricants and fuels (Patty 1963). Thus, exposure can occur in manufacturing aryl phosphates through inhalation and skin contact as well as ingestion of contaminated food (Tabershaw and Kleinfeld 1957, Patty 1963). It has also been of concern to those working with these cresyl containing compounds such as workmen on aircraft hydraulic systems (Baldridge et al. 1959, Patty 1963). It is a continuous health hazard because contamination can occur at any point in shipping and handling of these compounds.

TOTP is a compound which closely resembles organophosphate pesticides. This makes TOTP doubly important not only as an environmental contaminant, but as an experimental compound to investigate the toxic effects of phosphate pesticides.

Pesticides occupy a unique position among the many chemicals man encounters daily, in that they are deliberately added to the environment to kill or injure some form of life. Ideally, their actions would be highly specific for undesirable organisms. However, most of the chemicals that are used as pesticides are not highly specific and are generally toxic to many non-target organisms, including man. The mortality rate of man attributed to 
poisoning by pesticides has been estimated at 0.65 per million population in the United States, but it has also estimated that there are 100 nonfatal poisonings for each fatal one. Organophosphate pesticides are widely used and their property of relatively rapid degradation in the environment encourages even wider use as replacements for the more persistant organochlorine compounds.

The primary mode of toxic action of all organophosphorus pesticides, to a large degree, has been attributed to the inhibition of cholinesterase enzymes. The immediate cause of death in fatal poisonings being asphyxia resulting from respiratory failure. However, certain pesticide and related organophosphate compounds, including TOTP, possess an additional toxic effect. This effect is characterized by nervous system lesions that result in a form of paralysis which usually appears one to two weeks following exposure. Previous studies have concentrated on esterase inhibition in attempting to elucidate the mechanism of action. To date, no mechanism has been proposed which satisfactorily accounts for the neurotoxic syndrome.

Many studies have been done using TOTP concentrating on neurotoxicity and metabolism, but relatively little has been done concerning the immunological effects. The widespread use of organophosphate chemicals as pesticides and industrial compounds has created much concern as to their possible chronic as well as acute effects on the immunologic response of the exposed individuals.

It has been suggested that neurotoxic effects of chemicals may be related to an autoimmune phenomenon (O'Brien 1967). The 
involvement of autoimmunity in TOTP induced neurotoxicity in chickens was studied by Watanabe and Sharma (1977). Their results failed to demonstrate primary involvement of an autoimmune nature. An increase of chicken lymphatic filtration areas in spleen and liver was reported by Watanabe and Sharma (1976) but other organs did not show a similar response when exposed to TOTP. Also both total plasma levels and gamma-globulin:albumin ratios were greater in treated animals which suggests an immunological stimulation. However, there was no indication of any specific antibody present in plasma or organs (Watanabe and Sharma 1976).

The effects of chemicals on the immune system can be very damaging. Chemicals can produce autoantibodies which can produce dysfunction to parts of the body, or they may cause a malfunction in the normal antibody producing cells, thus greatly reducing the defense mechanisms of the body. The potential for immunological reactions due to exposure to these environmental and industrial chemicals exists. The immune system is a sensitive index of chronic toxicity, and should be considered in the toxicological evaluation of these chemicals. 
REVIEW OF LITERATURE

Tri-o-tolyl phosphate has been widely used to study the delayed neurotoxicity produced by certain organophosphate compounds. Based on the LD50, the anti-esterase TOTP metabolites were reported to cause paralysis at lower concentrations than TOTP in both mice and chickens (Bleiberg and Johnson 1965). This raises the question of whether unmetabolized TOTP is capable of producing paralysis without prior metabolism in other organs. Watanabe and Sharma (1975) showed that TOTP is capable of directly producing degenerative changes of nervous tissue in culture, although metabolized TOTP and DFP was observed to be more potent than TOTP itself. It is possible that TOTP is metabolized in the tissue culture. Morazain and Rosenberg (1970) reported that spinal cord tissues of chicken was incapable of converting TOTP to is anti-esterase metabolites in vitro, nor do the metabolites accumulate in these tissues.

\section{Toxic Effects}

Distribution data obtalned from an earlier study involving TOTP indicates significant accumulation of TOTP in the nervous tissue of the chicken. Further, the concentration is these tissues increased throughout a period of two weeks. The general trend in other tissues was to increase over 3-4 days then decline (Watanabe and Sharma 1973). 
TOTP has been shown to potentiate the effects of other compounds such as malathion (Murphy et a1. 1959). TOTP markedly increased the susceptibility of rats to malathion regardless of route of administration which is explainable on the basis of subsequent experiments which demonstrate that TOTP inhibits detoxification of malathion.

The hydrolysis of acrylate esters and acrylic acid in rat plasma and liver homogenates was significantly inhibited by treatment with TOTP. Apparently tissue carboxyesterases are involved in the detoxification of methyl acrylate and ethyl acrylate and that potentiation of acrylate ester toxicity may occur when carboxyesterase activity is inhibited (Silver and Murphy 1978).

\section{Animal Studies}

Laboratory animals also show delayed paralysis of the upper and lower extremities. Mice were reported to be $1 / 5$ to $1 / 25$ as susceptable to TOTP as cats, dogs, rabbits, etc., with a LD50 dose of $2.8 \mathrm{ml}$ per $\mathrm{kg}$ body weight (Hodge and Sterner 1943). Rats were shown to have an ora1 LD50 of $3000 \mathrm{mg} / \mathrm{kg}$ (Hodge and Sterner 1943), and $2500 \mathrm{mg} / \mathrm{kg}$ when administered in single doses intreperitoneally (Murphy et al. 1959). Meyers and Mendal in 1953 found that TOTP inhibited aliesterase activity of liver in rats. In the chicken, TOTP causes pathological alterations in the peripheral nervous system and definite lesions in the spinal cord (Bischoff 1959). 


\section{$\underline{\text { Pathologic Studies }}$}

Histopathologic studies of the peripheral nerves show that the distal fibers are affected earlier and more severely than proximal fibers. There is also a tendency of the large-diameter fibers to be affected more than small diameter fibers. Damage has also been reported of structures of the central nervous system, particularly the spinal cord where changes were characterized by occasional absence of the nucleolus, migration of the nucleus to the pexiphery and formation of the fine fatty granules in the cytoplasm of the cell. The results indicated that the multiple neuritis of this paralysis is essentially a degradation of the myelin sheaths of the peripheral nerves with a variable amount of relatively moderate central degenerative changes affecting the anterior horn cells throughout the spinal cord but more often in the lumbar and cervical regions (Smith and Lillie 1931).

This pattern of degeneration has come to indicate that a "dying back" process is occurring in these axons, and this is basically similar to certain distal degenerative conditions long recognized in man. It is assumed that in the "dying back" process there is a malfunction of the nerve cell that causes it to fall in maintaining its enormously long axon due to disturbed metabolism. Thus nutrients are not synthesized and transported at a sufficient rate to maintain the long axon of the peripheral nerves. It is also assumed that the metabolic process is disturbed to some degree in all nerve cells, but, with the doses of agent used or possible, 
the degree of disturbance is such as to impair the survival of only those fibers with the greatest demand for the maintenance process (Cavanagh 1969).

The general response to oral or parenteral administration of both alkly or aryl phosphates has been extensively reviewed. The onset of functional changes begins in the distal parts of the lower limbs, both in man and in all other sensitive animals, with mild sensory disturbances and motor weakness. This phenomena steadily progresses over the next few days, both in severity and in extent, and leads to increasing weakness and flaccidity of the legs and variable amounts of sensory disturbance of the 'stalking' type. The upper limbs may also be involved towards the end of this progressive phase of the poisoning, and again more changes are noted distally than proximally. After about three weeks the peak of the process is reached, and thereafter there is a steady improvement in the functional disturbances. Only in the mildest instances is recovery complete; a degree of residual disturbances may remain, due to variable amounts of damage to long spinal tracts that never recover, despite nearly complete regeneration of peripheral axons (Cavanagh 1969).

\section{Epidemiology}

Electrophysiological examinations performed on patients following poisoning with TOTP suggested the existence of the clinicoelectrophysiological forms of neuropathy. (1) The predominantly spinal form is characterized by a clinical picture 
resembling that in amyotrophic lateral sclerosis, a long course and persistence of residual signs of neuropathy for several years after ingestion of the toxic substance. (2) The predominantly neuropathic form is mixed, sensorimotor polyneuropathy, preddominantly motor and distal, involving especially the terminal parts of longer (peripheral) nerves. The electrophysiological data suggested a mixed process of demyelination and axonal degeneration, and that patients in the later stages of the disease showed that chances of recovery were good for those with PNS signs, but poor for those with CNS signs (Vasilescu 1979).

\section{Case Studies}

The first and classic cases of TOTP poisoning reported in the United States resulted from the drinking of liquors containing an illicit extract of Jamaica ginger used to circumvent the prohibition laws. Typically the victims reported onset of symptoms within 10 to 14 days after drinking the extract. Early symptoms included cramping muscular pain in the legs, followed by weakness. In most victims, quadriparesis and often frank quadreplegia with foot and wrist drop developed. Examination usually showed muscular weakness and wasting, with flaccidity and hypoactive reflexes most noticeable in the feet and legs; however, there were often diminished reflexes in the arms and hands. The typical syndrome was identified as a polyneuritis, sometimes called "motor neuritis" because of the paucity of sensory findings (Morgan 1978). 
Mass outbreaks of TOTP poisoning have occurred more recently in other countries. A dramatic poisoning which occurred in Morocco in 1959 was a result of contaminated "olive oil" used in cooking. The contaminating lubricating oil sold as such was man-made and was synthesized to withstand the very high temperatures required in turbo-jet aircraft engines (Smith and Spalding 1959). Another serious epidemic occurred in the Quang Tri Province of Viet Nam during 1970-71. The onset of this "Jake walk" was associated with the use of "black market" cooking oil, which on investigation proved to be a tri-o-tolyl phosphate containing U.S. military aviation lubricant supplied to South Vietnamese helicopter units (Dennis 1977).

A case of permanent paralysis in a man engaged in manufacturing tricresyl phosphate was described by Bidstrup and Bonnell (1954). While the final product contained only 1 percent of TOTP, as much as 6-10 percent was present as a contaminant during manufacturing. No exposure data was given, although the patient had worked a total of 5 months in that occupation before symptoms of anorexia, nausea, and aching of the legs had developed (Patty 1963).

\section{Related Phosphate Case Studies}

There are several phosphate esters that produce delayed neurotoxic effects. One such case involved Tetra-ethyl pyrophosphate (TEPP) in 1967. Because of a high mean value for the percentage of toxic dose received per hour of work, workers who were involved with the transportation of TEPP were investigated. Although 
there were several illnesses associated with this operation, the incidence was considered quite low in view of the relative hazard (Wolfe et a1. 1967).

Great Britain reported several cases of paralysis where symptoms resembled very closely to those of TOTP poisoning. The paralyssis developed in the third week after exposure to an organic phosphorous compound, bis-(mono-1sopropylamino)-fluorophosphine oxide (Mipafox). Like other organic phosphates used as pesticides, Mipafox is a inhibitor of cholinesterase in vitro and in vivo (Bidstrup and Bonnell 1953). Mipafox was also reported to produce demyelination in nerve tissue of rats exposed for 3 to 4 months. Similar results were observed in chickens treated with TOTP (Majno and Karnovsky 1961).

A small crises arose in the Bayport, Texas area in the early 1970 's over the noted cholinesterase Inhibitor Phosvel (Leptophos). Velsicol Chemical Corp. was the site of production where some 200 people were exposed. Several cases reported dizziness, blurred vision, numbness, and paralysis in the extremities (Alpern and Gram 1976). Leptophos has been shown to inhibit acetylcholinesterase, and monoamino oxidase. It causes irreversible symptoms of ataxia after 60 days exposure in lambs (E1-Sebae et al. 1977).

\section{Immunologic Studies Involving TOTP}

Although many studies have been completed using TOTP concentrating on neurotoxicity and metabolism, relatively little has been done concerning the immunological effects. O'Brien (1967) 
suggested that neurotoxic effects of chemicals may be related to an autoimunity phenomenon.

In a previous study on the toxicity of TOTP in the chicken, histopathologic examination of various lymphatic-related organs showed a definite increase of diffuse lympahtic tissue in the spleen and liver of TOTP-treated animals. Other organs did not show a similar response. However, the relative frequency and distribution of diffuse 1ymphatic tissue throughout the visceral organs were not uniform, which would cause difficulty in any evaluation. In this same study both total plasma protein levels and gamma-globulin:ratios were consistently greater at all sampling periods in the TOTP-treated animals, compared with controls (Watanabe and Sharma 1976). The results presented, although suggestive of an immunologic stimulation in the chicken, did not indicate the presence of any antibody against TOTP present in plasma or other organs (Watanabe and Sharma 1977).

In a subsequent study the involvement of autoimmunity in the pathogenesis of TOTP induced neurotoxicity in chickens was investigated. Immunosuppressive therapy including gamma-radiation and drug treatment was used to determine its effect on the neurotoxic syndrome. Wholebody radiation failed to show any consistent protection from TOTP induced paralysis. Drug therapy also indicated no protection. Thus the study was unable to demonstrate primary involvement of an autoimmune nature in the neurotoxicity produced by TOTP in the chicken (Watanabe and Sharma 1977). 
The Immune System

The immune system is composed of the cellular and humoral arms. Thus mediators of immune responses can be either freely diffusable antibody molecules of the immunoglobulin type in humoral immunity, or specifically reactive lymphocytes comprising the cellular type immunity. The immune system responds to many foreign or antigenic substances that enter the body. Their interactions with these antigens cause a production of antibodies (immunostimulation) or a decrease or destruction (immunosuppression) in the antibody response. Macrophages, although not antibody producers, play an important role in immunity because of their phagocytic properties, which also may be stimulated or inhibited by these antigens. The antibody forming response is initiated and regulated primarily by lymphatic cells derived from the bone marrow. Lymphocytes are relatively smal1, round, cells that are umbiquitous in blood, lymph, and connective tissues, and are of two fundamentally different kinds, $B$ and $T$ cells. The $B$ cells have abundant surface membrane-bound immunoglobulin molecules which are restricted in a given cell to molecules of a particular allotype, accounting for the cell's selective response to a given antigen. Some of these B cells differentiate into mature plasma cells (with the aid of $\mathrm{T}$ cell induction), the most active of all lymphoid cells in the synthesis and secretion of Igs. Many also revert back eventually into sma11 cells, which probably function as "memory cells". T cells, in contrast, have far fewer surface Igs and it is not certain that they are restricted in idiotype. The majority of the circulatory 
lymphocytes are $\mathrm{T}$ cells. They can become specific effector cells for cell-mediated immune responses: they can destroy tumor cells, cause rejection of allografts, and promote the differentiation of resting macrophages into highly bacteriocidal cells capable of destroying microbial pathogens (Davis et al. 1973).

Incubation with certain antigens cause small lymphocytes with the corresponding surface receptors to undergo blast transformation. The cells enlarge; the nucleolus swells; polysomes, rough endoplasmic reticulum, and microtubules develop; and rates of macromolecule synthesis increase markedly. Similar changes are initiated by the binding of certain plant and bacterial mitogens to the surface of $B$ and $T$ cells. These mitogens are specific for various sugars of different surface glycoproteins which are distributed equally on $\mathrm{B}$ and $\mathrm{T}$ cells. However, the two cell types respond differently. Phytohemagglutinin (PHA), a plant mitogen, stimulates transformation particulary in T cells. Lipo-polysaccharide (LPS), an endotoxin of gram-negative bacteria, is mitogenic for B cells. A plant protein, pokeweed mitogen (PWM), simulates transformation of both $B$ and $T$ cell types.

\section{Immunotoxicology and Enviromental Chemicals}

There is no single immunologic test that can completely assess the immune function; the system is a complex variety of interactive cellular compounds whose functions are often studied by monitoring secondary or tertiary events. The existance of a complex "feed back" interaction is only now being revealed and is far from 
understood. Toxicologists are in a quandry as to how to assess the immune system since they are inadequately trained in this area and are prone to conduct an immunotoxicity experiment that is not credible to the immunologist. Conversely, the immunologist possesses inadequate knowledge of chemistry or toxicology with the experimental results being exquisite immunological data that defies interpretation from a toxicologists point of view. Team efforts representing the best of both fields are essential (Moore 1979). 
MATERIALS AND METHODS

TOTP is a proven neurotoxic and prevalent industrial and environmental chemical. Investigations were conducted to determine if the compound illicites an effect on the immune system of mice. Several techniques were employed to test the cellular and humoral effects of repeated exposure of the animals to TOTP. The response of splenic lymphocytes to TOTP was determined by the ability of the $\mathrm{B}$ and $\mathrm{T}$ cells to undergo "blast transformation" or to proliferate in the presence of mitogens. PHA, PWM, and LPS were used for this purpose and tritiated-thymidine added to measure cellular development. The effects on the ability of the organism to produce specific gamma-globulins was determined by measuring their levels in the blood serum by immunoelectrophoresis. For additional parameters plaque formation and delayed hypersensitivity were also observed.

Two forms or isomers of this triester were used. Tri-o-tolyl phosphate was used in three dose levels and tri-m-tolyl phosphate in only the mid-dose level. This was to determine the general characteristic effects of these compounds.

\section{Anima1 Treatment}

Male Sim: (sw)fbr mice (weighing approximately $28 \mathrm{~g}$ each at the beginning of the experiment) were obtained from Simonsen Laboratories (Gilroy, California) and divided into five groups after ten days of 
acclimation. These animals were housed five per cage, and dosed with TOTP, TMTP cr corn oil.

TOTP solution was prepared by mixing $2500 \mathrm{mg}$ of TOTP (Eastman Kodak Co., Rochester, New York) with $50 \mathrm{ml}$ of corn oil. This stack solution, containing $50 \mathrm{mg} / \mathrm{ml}$ TOTP was diluted with corn oil to provide the appropriate solutions. TMTP solution for testing was prepared by mixing $250 \mathrm{mg}$ TMTP (Eastman Kodak Co.) with $50 \mathrm{ml}$ of corn oil. The control group received corn oil alone. The concentrations of all solutions were adjusted to provide $0.1 \mathrm{~m} 1$ per $10 \mathrm{~g}$ body weight to mice. The animals were weighed and dosed (gastric gavage method) once a week with $0.0,5.0,50$, and 500 $\mathrm{mg} / \mathrm{kg}$ of TOTP and $50 \mathrm{mg} / \mathrm{kg}$ of TMTP, for 13 weeks. Five animals were killed by decapitation for a pre-exposure control group. A flow chart for the experimental design follows.

\section{Design of Experiment}

Day

Methods and Animals Used

-10 Animals procured and kept for ten days for acclimation period. Total number $=155$.

0 Treatment began. Total animals $=150$

Control group $(\operatorname{corn}$ oil $)=30$

$5 \mathrm{mg} / \mathrm{kg}$ (ТОTР). . . . 30

$50 \mathrm{mg} / \mathrm{kg}$ (TOTP) . . . 30

$500 \mathrm{mg} / \mathrm{kg}$ (TOTP). . . 30

$50 \mathrm{mg} / \mathrm{kg}$ (TMTP) . . . 30 
Five animals in the pre-exposure control group were decapitated and tissue collected for testing. Lymphocyte transformation, five animals/group were killed and blood and organs collected for testing.

14 Challenged animals for Plaque formation with SRBCs. Five animals/group were treated with $0.25 \mathrm{ml}$ of a 20 percent solution.

18 Sensitized Delayed Hypersensitivity animals with $0.25 \mathrm{mls}$ of a 10 percent solution of SRBCs. Five animals/group. Second challenge of Plaque forming animals with SRBCs. Lymphocyte transformation, five animals/group were killed and tissue collected for testing. Plaque forming. Five animals/group were killed and plasma kept for electrophoresis.

Inoculate in foot-pad of delayed hypersensitivity animals. ${ }^{125}$ I labeled albumin injected IP. Delayed hypersensitivity, five animals/group were killed and feet collected for testing. Lymphocyte transformation, five animals/group were killed and tissues collected for testing. Lymphocyte transformation, five animals/group were killed and tissues removed for testing.

At the time of each kill the blood was collected, cell counts made and serum removed and frozen. Selected organs were collected and weighed. Liver, kidney, and thymus were placed in formalin while the spleens were saved in sterilized saline for lymphocyte cultures. 


\section{Spenic Lymphocyte Cultures}

Immediately after their collection, the spleens were washed with sterilized saline solution and mashed with forceps repeatedly in saline to release their cellular contents. The cells were separated from the intact tissue by serially passing the solution through 18, 21, and 25 gauge needles. The solution was allowed to stand for 10 minutes in a glass tube to remove the cell aggregates, after which it was transferred to a different tube removing the sediment and glass adherent materials. This suspension was centrifuged at 2000 rpins for 10 minutes at room temperature. The cell pellet was resuspended in $4 \mathrm{ml}$ of culture media and an aliquot was used for counting the number of 1ymphocytic cells in a Coulter counter after lysis of erythrocytes.

Lymphacyte transformation was determined on the cuiture by a method modified from that of Sharma and Gehring (1979). The culture media used was RPMI-1640 (Grand Island Biologicals, Grand Island, N.Y.) containing 10 percent heatinactivated fetal calf serum and 100 units of penicillin and 100 Hg of streptomycin per $\mathrm{ml}$. The media was supplemented with $3 \mathrm{mg} / \mathrm{ml}$ of L-glutamine. The suspension was adjusted to provide approximately $8 \times 10^{6} \mathrm{cells} / \mathrm{ml}$ and $50 \mu 1$ of this layered into each well of a micro-tissue-culture plate (Microtest II. Falcon 3042). To each wel1, $50 \mu 1$ of additional media was added and $50 \mu 1$ of media either with or without mitogen was also added. Mitogens PHA, PWM, and LPS were obtained from GIBCO. The plates were incubated 
for 52 hours at $37^{\circ} \mathrm{C}$ in humidified 5 percent $\mathrm{CO}_{2}$ in air atmosphere. After this incubation period, $50 \mu 1$ of media containing $0.5 \mu \mathrm{Ci}$ of tritiated-thymidine (New England Nuclear) was added to each well and the incubation continued for an additional 16 hours. The cells were harvested and vigorously washed with physiological saline using a model M12 cell harvester and collected on glass fiber discs (Whatman, Grade 934-AH). These discs were placed directly in regular counting vials, $6 \mathrm{ml}$ of scintillation solution added and radioactivity counted in a scintillation spectrometer (Packard, TriCarb 2660). All cultures were run in triplicates. The Relitive Proliferation Index (RPI) (Koller et a1. 1970) for PHA, PWM, and LPS were calculated by dividing the net cpm of the test groups (mitogen-stimulated) by the net cpm of the control group (unstimulated). A Stimulation Index (SI) was also calculated by dividing the cpm of the mitogen stimulated cells by the unstimulated cells for each animal.

\section{Plaque Formation}

Five mice in each dosage level were randomly selected and inoculated intraperitoneally with $0.25 \mathrm{ml}$ of a 20 percent suspension of sheep red blood cells 14 and 7 days before sacrifice. The spleen from each mouse was removed with forceps and forced through 18, 21, and 26 gauge needles. The spleen cell suspension was counted in the Coulter counter and adjusted to approximately $1 \times 10^{7}$ cells per ml. The number of plaque forming cells (PFC) was measured according to a method of Cunningham and Szenberg 
(1968). Four pieces of double-sided tape, each $\frac{1}{4}$ in. wide were laid across a clean microscope slide dividing it into three areas. One large precleaned cover slip was pressed firmly onto the tape to form three shallow chambers. A mixture containing 45 percent splenic cells, 45 percent of a 10 percent suspension of SRBCs, and 10 percent pooled guinea-pig complement (Miles Laboratories, Elkhart, Indiana) in deluent, was delivered by a pasture pipette into each chamber. The chambers were sealed with a mixture of petroleum jelly and mineral oil, and incubated at $37^{\circ} \mathrm{C}$ for 30 minutes. The plaques were counted using a microscope. The number of plaques per million splenic cells was calculated from the number of plaques observed per microliter of the initial mixture.

\section{Delayed Hypersensitivity: Radioisotope Food-Pad Assay}

Five mice per dose level were randomly selected and immunized with $0.25 \mathrm{ml}$ of SRBCs (10 percent). Ten days later each group was injected in the right food pad with $0.02 \mathrm{ml}$ of the same dilution of SRBCs. Immediately thereafter, ${ }^{125}$ I-labeled bovine serum albumin was injected i.p. into the mice. The radioiodine-labeled protein was prepared as described by Boone, Irving, and Rubenstein (1971). The usual dose per mouse was $5.0 \mu \mathrm{Ci}$ in $0.10 \mathrm{~m} 1$. The mice were killed 24 hours later and the test and control feet cut of $\mathrm{f}$ at the junction of the lower and middle thirds of the tibia and counted in a gamma spectrometer (Abbott Laboratories, Auto-logic 7407). Results were expressed as the "foot-count ratio": counts per minute given by the test food divided by counts per minute given by the control feet (Vadas et a1. 1975). 


\section{Quantitative Immunoelectrophoresis}

Blood taken from animals that had been challenged with SRBCs was centrifuged and serum drawn off. This serum was used to test for IgA, IgG, and IgM immunoglobulins. The standard serum run against the test serum was collected from five untreated mice and pooled.

The method used was modified from Bjerrum et al., (1973). Agarose (1 percent) obtained from Bio-Rad (Richmond, Va.) was prepared and mixed with carbamylated antiglobulins. Goat antimouse immunoglobulins (Miles Lab., Elkhart, Indiana) was used. This mixture was poured onto plates $(10 \mathrm{~cm} \mathrm{x}$ $10 \mathrm{~cm}$ ) to provide a thickness of approximately $1.5 \mathrm{~mm}$.

Wells were formed in the plates and samples of each mouse serum was added to each in $2 \mu 1$ quantitites. Each plate also contained samples of the standard. All samples, standard as well as test, were run in duplicate. Serum was diluted to a 1:10 ratio. The plates were immediately placed in the electrophoresis cell (Mode1 1400 horizontal gel type, Bio-Rad Lab.) containing TEMED buffer ( $\mathrm{pH}$ 5). Electrophoresis was conducted (toward the cathode) for three hours (fast, 300 volt) or over night (slow, 100 volts).

After electrophoresis, the gel plates were fixed in 7 percent TCA for 15 minutes and then washed in water for 5 minutes. The gels were then pressed for 10 minutes and dried thoroughly. Dried gels were stained with Amino Black for an additional 15 minutes and then decolorized for a few minutes in a destaining solution. 
Plates were then dried and rockets identified. Heights of the standard serum and test serum were compared and the percent of standard for the test serum calculated.

\section{Statistical Manipulation and Data Presentation}

Lymphocyte transformation data is presented in tabular form as Relative Proliferation and Stimulation Indices for PHA, PWM, and LPS in splenic cultures in relationship to time and amount of TOTP exposure. RPI's are also presented in graphical form for each mitogen. The effects of TOTP on body and organ growth was tabulated and presented as $\mathrm{g} / 100 \mathrm{~g}$ of body weight. Plaque forming cells were presented as PFCs per million splenic 1ymphocytes, and delayed hypersensitivity as foot-count ratio. A comparison of while blcod WBCs and RBCs was also calculated. Electrophoretic rocket heights were taken and test serum presented as percent of standard in relation to TOTP dosage level. All data was tested for significant changes from the control groups by using a twotailed Dunnett's t test (Dunnett 1955). 
RESULTS

In mice, TOTP and TMTP exposure for 13 weeks produced no significant effects on growth, or weights of spleen, liver, kidney, and thymus (Table 1). At the time of termination, several mice in the high dose level had a slight discoloration of the ears, tail, and feet as well as the internal organs. However, no significant difference was noted in any of the parameters tested.

\section{Splenic Lymphocyte Cultures}

Relative Proliferation and Stimulation Indices of lymphatic uptake of thymidine were calculated for spenic cultures using PHA, PIM, and LPS for mitogenic induction (Table 2). The stimulation index showed an increase of thymidine uptake by only PWM at 4 weeks, there was a decrease at 8 and 13 weeks for both PHA and PWM but not LPS.

The relative proliferation index indicated no significant change from the control for PHA (Figure 1). PWM, however, showed a decrease at 8 weeks for the $500 \mathrm{mg} / \mathrm{kg}$ TOTP and $50 \mathrm{mg} / \mathrm{kg}$ TMTP, and at 13 weeks for all dose levels (Figure 2). LPS induction was affected only at the 4 week period fro the low and mid-dose levels (Figure 3). Thus an overall trend points toward a decrease in mitogenic stimulation as time of treament increases. 
Table 1. Organ and body weights of mice treated with different dose levels of TOTP and TMTP.

\begin{tabular}{|c|c|c|c|c|c|c|c|c|c|c|}
\hline \multirow[b]{3}{*}{ Week } & \multirow[b]{3}{*}{ Dose } & \multirow{3}{*}{$\begin{array}{l}\text { Body } \\
\text { height } \\
\text { (g) }\end{array}$} & \multicolumn{6}{|c|}{ Drgan Weights and Their Relation to Body Welght } & \multirow{2}{*}{\multicolumn{2}{|c|}{ Thymus }} \\
\hline & & & \multicolumn{2}{|c|}{ Spleen } & \multicolumn{2}{|c|}{ Liver } & \multicolumn{2}{|c|}{ Kidney } & & \\
\hline & & & $(\mathrm{B})$ & $(\mathrm{g} / 100 \mathrm{~g})$ & (g) & $(\mathrm{B} / 100 \mathrm{~g})$ & (B) & $(\mathrm{g} / 100 \mathrm{~g})$ & (G) & $(g / 100 g)$ \\
\hline 0 & 0 & $31.1(.24)$ & $0.11(.01)$ & $0.40(.05)$ & $1.91(.13)$ & $6.57(.51)$ & $0.51(.02)$ & $1.75(.13)$ & $0.08(.02)$ & $0.29(.04)$ \\
\hline \multirow[t]{5}{*}{1} & 0 & $31.5(.54)$ & $0.15(.04)$ & $0.48(.12)$ & $2.04(.07)$ & $6.50\{.06\}$ & $0.50(.03)$ & $1.59(.02)$ & $0.05(.01)$ & $0.18(.01)$ \\
\hline & 5 & $31.8(2.7)$ & $0.16(.02)$ & $0.52(.06)$ & $2.00(.12)$ & $6.40(.25)$ & $0.51(.02)$ & $1.63(.11)$ & $0.08(.02)$ & $0.26(.09)$ \\
\hline & 50 & $28.8(2.5)$ & $0.21(.04)$ & $0.82(.26)$ & $1.80(.26)$ & $6.26(.21)$ & $0.50(.03)$ & $1.75(0.8)$ & $0.05(.01)$ & $0.18(.03)$ \\
\hline & 500 & $32.4(1.5)$ & $0.18(.03)$ & $0.56(.13)$ & $2.35(.13)$ & $7.32(.59)$ & $0.54(.03)$ & $1.67(.06)$ & $0.07(.01)$ & $0.18(.04)$ \\
\hline & $50 M$ & $33.0(.45)$ & $0.12(.01)$ & $0.37(.03)$ & $2.00(.07)$ & $5.91(.17)$ & $0.52(.02)$ & $1.59(.07)$ & $0.06(.01)$ & $0.18(.02)$ \\
\hline \multirow[t]{5}{*}{4} & 0 & $35.3(1.5)$ & $0.13(.01)$ & $0.36(.02)$ & $2.18(.08)$ & $6.18(.0 B)$ & $0.56(.02)$ & $1.57(.03)$ & $0.07(.01)$ & $0.19(.02)$ \\
\hline & 5 & $35.1(1.4)$ & $0.14(.03)$ & $0.41(.03)$ & $2.01(.13)$ & $5.71(.20)$ & $0.56(.04)$ & $1.59(.04)$ & $0.07(.01)$ & $0.19(.07)$ \\
\hline & 50 & $38.2(1.7)$ & $0.16(.01)$ & $0.41(.02)$ & $2.33(.12)$ & $5.09(.12)$ & $0.57(.04)$ & $1.49(.07)$ & $0.07(.01)$ & $0.18(.01)$ \\
\hline & 500 & $32.5(1.9)$ & $0.15(.02)$ & $0.45(.05)$ & $2.04(.14)$ & $6.29(.25)$ & $0.15(.02)$ & $1.57(.02)$ & $0.06(.01)$ & $0.16(.02)$ \\
\hline & $50 M$ & $35.5(2.5)$ & $0.27(.07)$ & $0.78(.25) *$ & $2.14(.17)$ & $5.89(.07)$ & $0.57(.03)$ & $1.58(.03)$ & $0.05(.01)$ & $0.12(.02)$ \\
\hline \multirow[t]{5}{*}{8} & 0 & $40.4(2.7)$ & $0.20(.02)$ & $0.48(.04)$ & $2.40(.21)$ & $5.93(.19)$ & $0.59(.05)$ & $1.45(.05)$ & $0.06(.01)$ & $0.16(.02)$ \\
\hline & 5 & $36.9(2.6)$ & $0.23(.02)$ & $0.52(.04)$ & $2.40(.27)$ & $6.41(.30)$ & $0.55(.04)$ & $1.49(.03)$ & $0.05(.01)$ & $0.13(.02)$ \\
\hline & 50 & $35.1(2.2)$ & $0.20(.02)$ & $0.56(.02)$ & $1.94(.18)$ & $5.51(.23)$ & $0.51(.0+1)$ & $1.46(.07)$ & $.0 .07(.01)$ & $0.20(.01)$ \\
\hline & 500 & $37.7(2.0)$ & $0.23(.05)$ & $0.61(.15)$ & $2.97(.38)$ & $7.92(1.0) *$ & $0.59(.03)$ & $1.57(.06)$ & $0.05(.01)$ & $0.14(.02)$ \\
\hline & $50 M$ & $39.3(2.5)$ & $0.20(.02)$ & $0.52(.03)$ & $2.48(.15)$ & $6.32(.17)$ & $0.56(.04)$ & $1.44(.08)$ & $0.06(.01)$ & $0.14(.01)$ \\
\hline \multirow[t]{5}{*}{13} & 0 & $42.7(2.4)$ & $0.25(.05)$ & $0.38(.09)$ & $2.60(.09)$ & $6.14(.31)$ & $0.71(.03)$ & $1.56(.04)$ & $0.06(.01)$ & $0.19(.01)$ \\
\hline & 5 & $44.4(.55)$ & $0.18(.02)$ & $0.42(.06)$ & $2.90(.08)$ & $5.71(.17)$ & $0.76(.02)$ & $1.59(.05)$ & $0.05(.01)$ & $0.19(.02)$ \\
\hline & 50 & $43.3(1.8)$ & $0.22(.02)$ & $0.51(.04)$ & $2.68(.15)$ & $6.18(.16)$ & $0.70(.07)$ & $1.49(.09)$ & $0.06(.01)$ & $0.18(.01)$ \\
\hline & 500 & $46.5(3.0)$ & $0.23(.03)$ & $0.43(.05)$ & $2.88(.30)$ & $6.14(.26)$ & $0.74(.09)$ & $1.57(.10)$ & $0.06(.01)$ & $0.15(.01)$ \\
\hline & $50 M$ & $43.7(1.3)$ & $0.23(.02)$ & $0.52(.06)$ & $2.78(.15)$ & $6.35(.22)$ & $0.68(.03)$ & $1.55(.05)$ & $0.06(.01)$ & $0.13(.02)$ \\
\hline
\end{tabular}

*p<0.05 using Dinnett's test for signiftcance between treated and control we an values. Parenthests a standard error of the mean. $M=T$ TIT . 


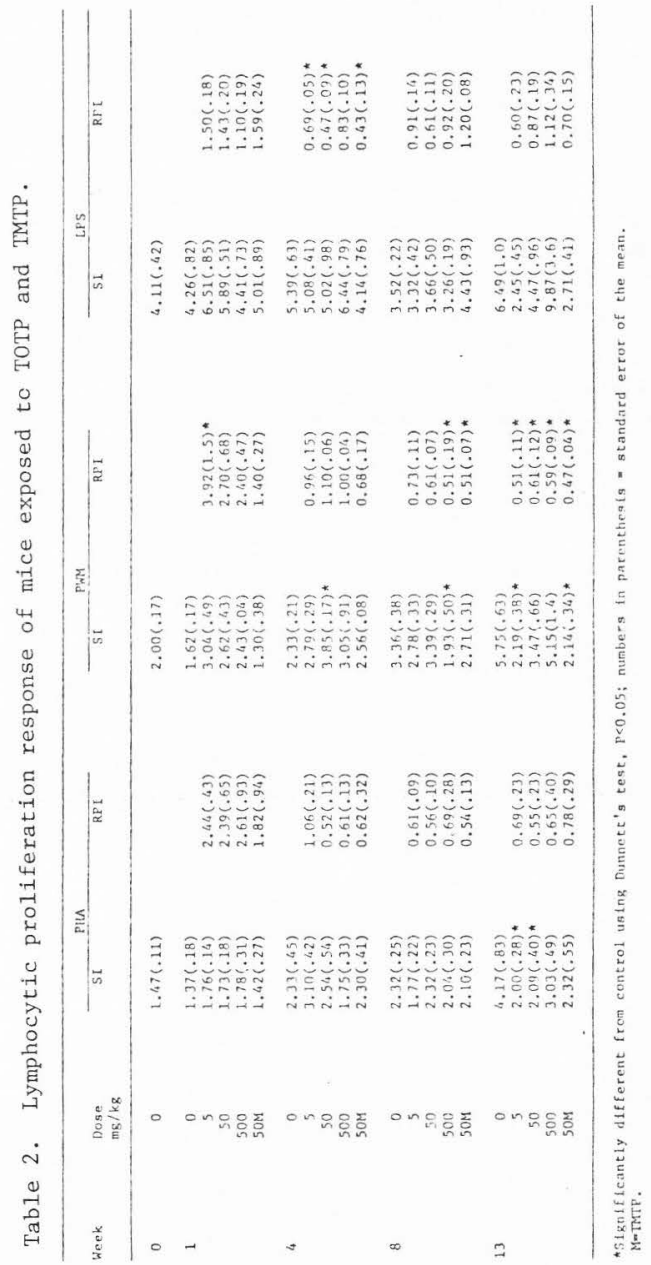




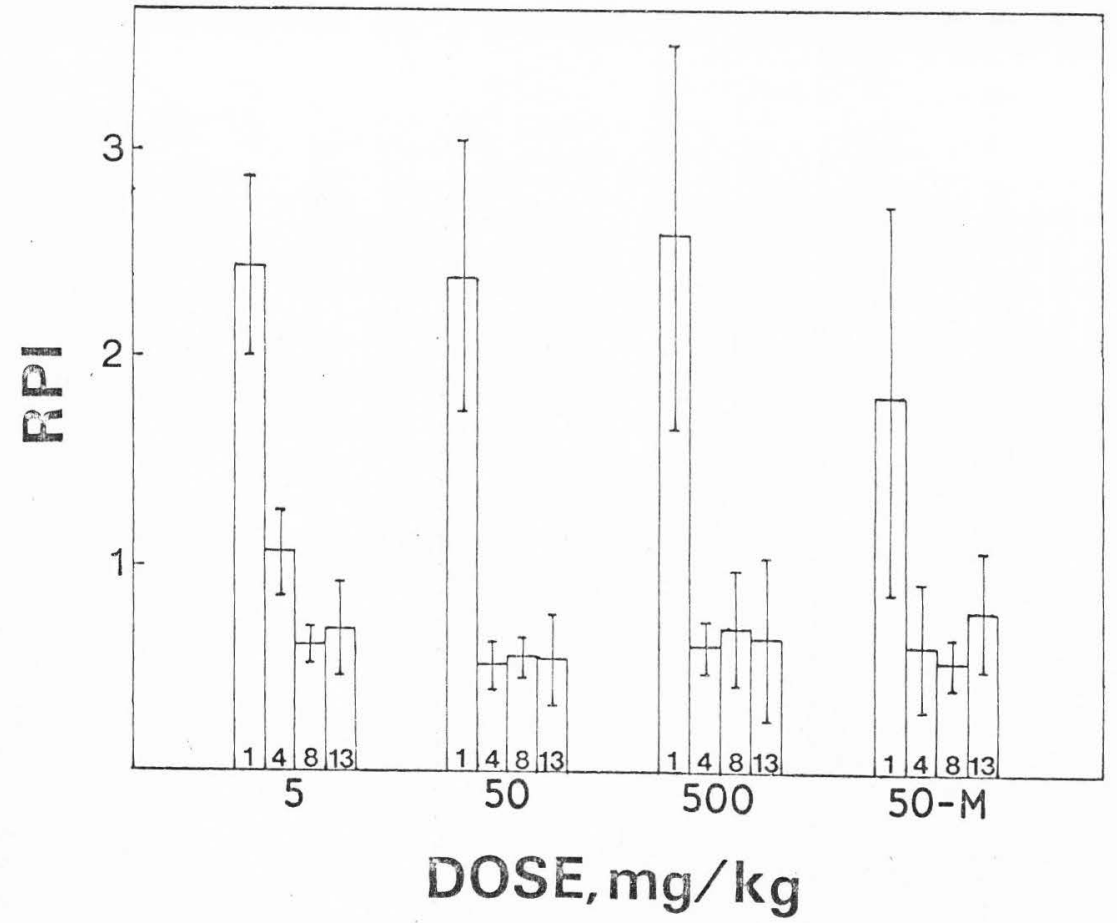

Figure 1. Relative proliferation index of splenic 1ymphocyte cultures to PHA. RPI = net cpm of test groups divided by net cpm of control groups. Vertical bars represent standard error of mean and * indicates a significant change from the control at $\mathrm{P}<0.05 . \mathrm{M}=$ TMTP. 


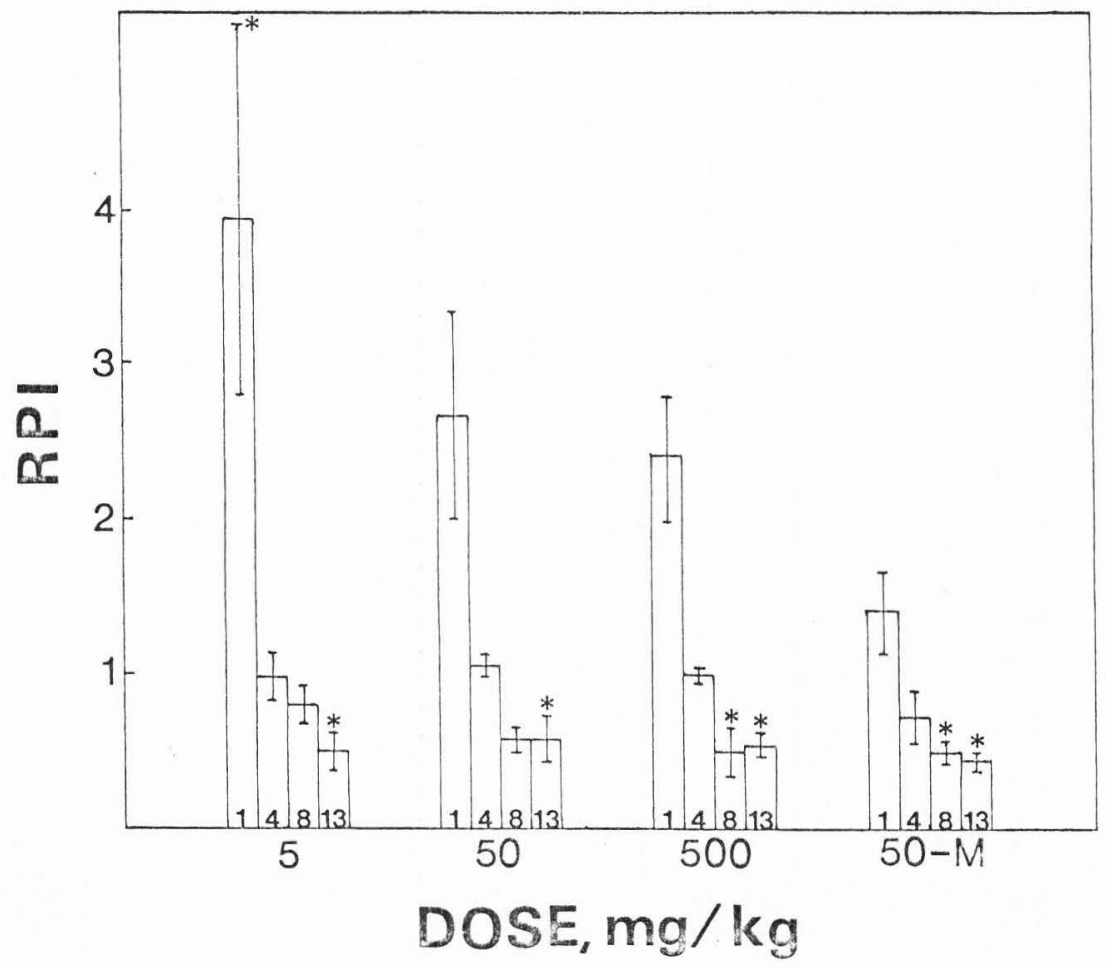

Figure 2. Relative proliferation index of splenic lymphocyte cultures to PWM. RPI = net cpm of test groups divided by net cpm of control group. Vertical bars represent standard error of mean and * indicates significant difference from control at $\mathrm{P}<0.05 . \quad \mathrm{M}=$ TMTP. 


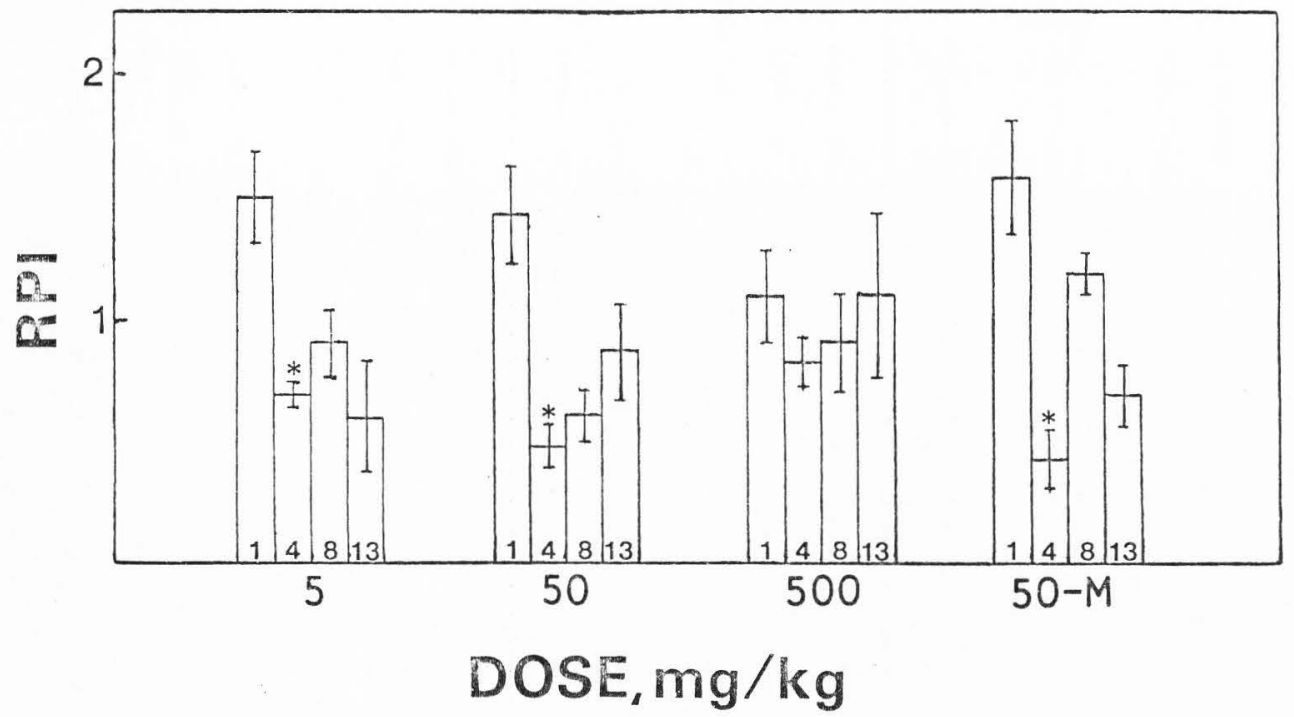

Figure 3. Relative proliferation index of splenic lymphocyte cultures to LPS. RPI = net cpm of test groups divided by net cpm of control groups. Vertical bars represent standard error of mean and * indicates value significantly different from control at $\mathrm{P}<0.05$. $M=$ TMTP. 


\section{Plaque Formation}

Plaque forming cells were calculated per million splenic cells (Table 3). Because of relatively high standard error of the means no change was noted from the controls using Dunnett's test for significance.

\section{Delayed Hypersensitivity}

Delayed hypersensitivity inflammatory response was tested by use of radioisotopic label. Foot count ratio was tabulated by dividing the counts of the test foot with those of the control foot. Results of this were negative with no significant difference from the control (Table 3).

\section{Quantitative Immunoelectrophoresis and Hematology}

Serum immunoglobuline, IgA, IgG, and IgM in mice at different levels of TOTP exposure are shown in Table 4. These were calculated as percent of pooled serum used as standard. The control serum was obtained from mice of the same strain without treatment and pooled. No significantly different changes were noted in the treated groups as compared to the control group.

No apparent change took place in whole blood erythrocyte and lymphocyte counts as shown in Table 5. There was an increase in RECs at the mid dose levels of TOTP and also TMTP after 1 week and at the mid dose level of TOTP after 13 weeks. No change was found in the white cell count at any dosage or time interval. 
Table 3. Plaque forming cells and delayed hypersensitivity foot count ratio.

\begin{tabular}{rrc}
\hline Dose, mg/kg & PF cells & count ratio \\
\hline 0 & $918(294)$ & $1.15(.03)$ \\
5 & $1079(164)$ & $1.12(.02)$ \\
50 & $629(137)$ & $1.37(.17)$ \\
500 & $596(78)$ & $1.33(.12)$ \\
$50 \mathrm{M}$ & $527(118)$ & $1.17(.07)$ \\
\hline
\end{tabular}

Note: Plaque forming cells tabulated per million splenic lymphocytes. Foot count ratio was with ${ }^{125}$ I label. Standard error of the mean in parenthesis. $M=$ TMTP.

Table 4. Quantitative immunoelectrophoresis of mouse serum immunoglobulins.

\begin{tabular}{rrrr}
\hline Dose, mg/kg & \multicolumn{1}{c}{ IgA } & IgG & \multicolumn{1}{c}{ IgM } \\
\hline 0 & $118(5)$ & $92(9)$ & $95(1)$ \\
5 & $88(2)$ & $102(11)$ & $103(2)$ \\
50 & $103(4)$ & $83(5)$ & $102(2)$ \\
500 & $99(9)$ & $101(9)$ & $99(2)$ \\
$50 M$ & $112(12)$ & $87(5)$ & $95(4)$ \\
\hline
\end{tabular}

Note: Calculated as percent of standard pooled mouse serum. Standard error of the mean in parenthesis. $M=$ TMTP. 
Table 5. Whole blood erythrocyte and lymphocyte counts.

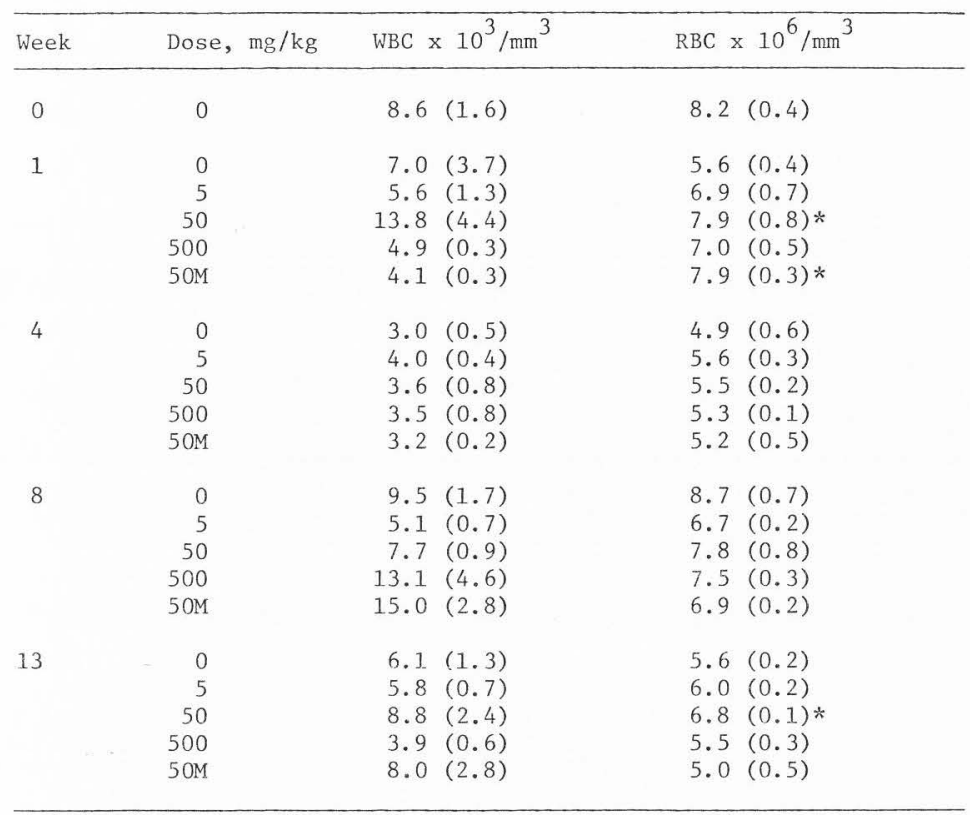

$\star$ Significantly different from control using Dunnett's test, $\mathrm{P}<0.05$. Numbers in parenthesis = standard error of the mean. $M=$ TMTP.

Note: WBC and $\mathrm{RBC}$ are in counts/cubic millimeter. 


\section{DISCUSSION}

Tri-o-tolyl phosphate, a prevalent industrial and environmental chemical, is similar in structure as well as toxic action to many organophosphate compounds. TOTP is a very toxic nerve agent and has been involved in several poisonings in man (Morgan 1978). Not only TOTP itself but its metabolites have been found to accumulate and produce degenerative effects in nervous tissue (Watanabe and Sharma 1975).

Many possible explanations have been postulated for its mode of toxic action. Inhibition of cholinesterases, direct degradation of the myelin sheath, failure to maintain the nerve's basic metabolism, and effects related to autoimmunity have been reported (Silver and Murphy 1978, Smith and Lillie 1931, Cavanagh 1969, O'Brien 1967).

This project was undertaken to study the effects of TOTP on the ability of 1ympahtic cells to proliferate and produce antibodies. A 90-day oral administration to TOTP up to $500 \mathrm{ng} / \mathrm{kg}$ in mouse produced no effect on growth rate or organ weight of the animals.

Splenic lymphocytes were cultured in vitro with three known mitogens for $52 \mathrm{hrs}$, and their ability to proliferate measured by addition of radioisotope labeled tymidine. TOTP had relatively littel effect on the 1ymphocytes when stimulated with PHA. However, at both 4 and 13 weeks the PWM and LPS assays indicated that TOTP at all doses and especially the mid and high levels caused a 
suppression of lymphocyte activity. TMTP had only slight suppressive action according to PWM. Although this action was non-specific and not dose related it coincides with an earlier study done by Watanabe and Sharma (1976) where Iymphocytic tissue was noted to be more diffuse after treatment with TOTP in the chicken.

The results of the plaque formation study showed no significant trends for the various treatment groups which suggested that lymphatic activity was not affected by TOTP. Likewise, the delayed hypersensitivity test showed similar results in that no significant relationship was seen between doses of TOTP and in foot count ratios. Therefore, the hypersensitivity reaction does not appear to be affected by this organophosphate compound. It was reported by Watanabe and Sharma (1976) that plasma protein levels and gammaglobulin:albumin ratios were consistently greater for TOTP treated animals versus control. Our results, however, failed to show any consistent increase or decrease in IgA, IgG, and IgM immunoglobulin levels when compared to standard serum. This suggests no immunotoxicologic involvement of TOTP on serum proteins.

Exposure to certain environmental contaminants has resulted in marked effects on antibody synthesis (Koller et al. 1974, 1975). In a recent study by Koller et al. (1976) leptophos was shown to cause organophosphate poisoning, but did not significantly alter antibody formation to a specific antigen (SRBC). Primary and secondary immune responses were tested for by the hemolytic plaque assay, therefore leptophos apparently does not interfere with the humoral tissue system. Several organophosphate pesticides have been reported to affect the immune system. Rats exposed to methylnitrophos, 
chlorophos, and triufon were reported to have decreased hemagglutination titers, complement levels (Shtenberg et al. 1974), and size of splenic lymphoid follicles (Dinoeva 1974). Following exposure to anthio the ability of neutrophils to phagotcytize was diminished in goats (Aripdzhanov 1973). Methylparathion (Street and Sharma 1975) decreased the number of globulin producing cells in the popiteal lymph nodes of rabbits but had no effect on the hemolysis of hemagglutination titer to SRBC antigen. Conflicting data concerning the effects of organophosphate pesticides on immunity indicate the action of the pesticide nay be dependent upon several factors such as the compound configuration, method of exposure, and type of antigen. It is also conceivable that only certain organophosphates affect immunity or that only certain species of animals are susceptible.

In conclusion, at the dose levels used in this study, ToTP produced no significant effects on the immune system of mice as determined by several in vitro assays of immunocompetence. Organophosphate poisoning was evident by moderate discoloration and scruffy appearance of mice that received $500 \mathrm{mg} / \mathrm{kg}$ TOTP. This was interpreted to be clinical signs of organophosphate stress. 


\section{SUMMARY}

Male Swiss Webster mice exposed to 5, 50, $500 \mathrm{mg} / \mathrm{kg}$ TOTP and $50 \mathrm{mg} / \mathrm{kg}$ TMTP for 13 weeks showed no significant difference in body and organ weights in relation to dosage and time of treatment. Splenic lymphocytes (obtained at 1, 4, 8, and 13 weeks) cultured in vitro with mitogens PHA, PWM, and LPS showed a stimualtion for all dose levels at 4 weeks. Thereafter a suppression was observed especially with PWM and LPS stimulated cultures. Although there was a definite suppressive trend at 8 and 13 weeks it was not dose related and not always statistically significant and therefore non-specific.

other parameters tested; plaque formation by splenic cells, delayed hypersensitivity, and immunoelectrophoresis, showed no significant changes from the control groups.

Thus at the treatment levels used, TOTP, produced no significant effects on the immune system of mice as determined by these in vivo and in vitro assays of immunocompetence. 


\section{LITERATURE CITED}

Alpern, D. M. and D. Gram. 1976. The phosve1 zombies. Newsweek Dec. 13.

Aripdzhanov, T. M. 1973. Experiment study of the effect of Antio and Milbex on immunological reactivity and some autoimmunological processes in the organism. Gig. Sanit. 5:101-102.

Baldridge, H. D., D. J. Jenden, C. E. Knight, T. J. Preziosi, and J. R. Tureman. 1959. Toxicology of a triaryl phosphate oil. III. Human exposure in operational use aboard ship. AMA Arch. Indust. Health 20:258-261.

Bidstrup, P. L. and J. A. Bonnell. 1954. Paralysis following poisoning by a new organophosphate insecticide. Brit. Med. J. L:1068-1072.

Bischoff, A. 1959. Ultrastructure of tri-ortho-cresyl phosphate. Poisoning in the chicken. Acta Neuropath. 15:142-155.

Bjerrum, 0. J., A. Ingild, H. Lowenstein, and B. Weeke. 1973. Quantitation of human IgG by rocket immunoelectrophoresis at $\mathrm{pH} 5$ by use of carbamylated antibodies. A ruutine laboratory method. C1in. Chem. Acta 46:337-338.

Bleiberg, M. J. and H. Johnson. 1965. Effects of certain metabolically active drugs and oximes on tri-o-cresyl phosphate toxicity. Toxicol. Appl. Pharmacol. 7:227-235.

Boone, C. W., D. N. Irving, and S. Rubenstein. 1971. Quantitative studies on the binding of antibody to the surface of HeLa cells. J. Immuno1. 106:879-881.

Cavanagh, J. B. 1969. Toxic substances and the nervous system. Brit. Med. Bu11. 25:268-273.

Cunningham, A. J. and A. Szenberg. 1968. Further improvements in the plaque technique for detecting single antibody forming cells. Immunology 14:599-601.

Davis, B. D., R. Dulbecco, H. N. Eisen, H. S. Ginsberg, and W. B. Wood. 1973. Microbiology, Second Edition. pp. 389, 450-563. Harper \& Row, New York.

Dennis, D. T. 1977. Jake Walk in Vietnam. Ann. Intern. Med. $86: 665-666$. 
Dinoeva, S. K. 1974. Dynamics of changes in the immune structure of lymphatic follicles of the spleen during pesticide poisoning. Gig. Sanit. 3:85-87.

Dunnett, C. W. 1955. A multiple comparison procedure for comparing several treatments with a control. J. Amer. Statist. Ass., $50: 1096-1121$.

E1-Sebae, A. H., S. A. Soliman, M. AboElamayem, and N. S. Ahmed. 1977. Neurotoxicity of organophosphorus insecticides: leptophos and EPN. J. Environ. Sci. Health B12:269-288.

Hodge, H. C. and J. H. Sterner. 1943. The skin absorption of tri-ortho-cresyl phosphate as shown by radioactive phosphorus. J. Pharmacol. Exp. Thearp. 79:225-227.

Koller, L. D. and S. Kovacic. 1974. Decreased antibody formation in mice exposed to 1ead. Nature 250:148-150.

Koller, L. D. J. H. Exon, and J. G. Roan. 1975. Antibody suppression by cadmium. Arch. Environ. Health 30:598-601.

Koller, L. D., J. H. Exon, and J. G. Roan. 1976. Immunological surveillance and toxicity in mice exposed to the organophosphate pesticide, leptophos. Environ. Research 12:238-242.

Koller, L. D. J. G. Roan, and N. I. Kerkvliet. 1979. Evaluation of data from mitogen studies in CBA mice: comparison of counts per minute, stimulation index and relative proliferation index. Amer. J. Vet. Res. 40:863-866.

Majno, G. and M. L. Karnovsky. 1961. A biochemical and morphological study of myelination and demyelination. III. Effects of an organophosphorus compound. J. Neurochem. 8:1-7.

Moore, J. A. 1979. The immunotoxicologic phenomenon. Drug and Chem. Toxicol. $2: 1-4$.

Morazain, R. and P. Rosenberg. 1970. Lipid changes in tri-o-cresyl phosphate-induced neuropathy. Toxicol. Appl. Pharmacol. $16: 461-474$.

Morgan, J. P. 1978. Jamacia ginger paralysis, forty-seven year follow up. Arch. Neurol. 35:530-532.

Murphy, S. D., R. L. Anderson, and K. D. DuBois. 1959. Potentiation of toxicity of malathion ty TOTP. Soc. Exp. Biol. Med. 100: 483-487.

O'Brien, R. D. 1967. Insecticides: Action and Metabolism. p. 59. Academic Press, New York. 
Patty, F. A. 1963. Industrial Hygiene and Toxicology, Second Edition. p. 1919-1923. John Wiley and Sons, Inc., New York.

Shtenberg, A. I., L. Khovaeva, and M. V. Zavarzin. 1974. Effect of chlorophos and methylnitrophos on the immune reactions of the organisms against the background of protein-deficient nutrition. Vopr. Pjtan. 4:35-42.

Sharma, R. P. and P. J. Gehring. 1979. Effects of 2, 3,7,8tetrachlorodibenzo-p-dioxin on spleen lymphocyte transformation in mice after single and repeated exposures. Ann. N. Y. Acad. Sci. 320:487-897.

Silver, E. H. and S. D. Murphy. 1978. The effect of carboxylesterase inhibition on the toxicity of methyl acrylate, ethyl acrylate and acrylic acid. Toxicol. App1. Pharmaco1. 45:312313.

Smith, H. V. and J. M. K. Spalding. 1959. Outbreak of paralysis in Morocco due to ortho-cresyl phosphate poisoning. Lancet $2: 1010-1021$.

Smith, M. I. and R. D. Lillie. 1931. The histopathology of triortho cresyl phosphate poisoning. Arch. Neurol. Psychiatr. $26: 976-992$.

Street, J. C. and R. P. Sharma. 1975. Alterations of induced cellular and humoral immune responses by pesticides and chemicals of environmental concern: Quantitative studies of immunosuppression by DDT, Aroclor 1254, carbary1, carbofuran, and methyl-parathion. Toxicol. Appl. Pharmacol. 32:587-602.

Tabershaw, I. R. and M. Kleinfeld. 1957. Manufacture of tricresyl phosphate and other alkayl pheny1 phosphates: an industrial hygiene study. AMA Arch. Indust. Health 15:541-544.

Vadas, M. A., J. F. A. P. Miller, J. Gamble, and A. Whitelaw. 1975. A radioisotopic method to measure delayed type hypersensitivity in the mouse. Int. Arch. Allergy App1. Immunol. 49:670-692.

Vasilescu, C. 1979. Triorthocresyl phosphate neuropathy. Arch. Neurol. $36: 455$.

Watanabe, P. G.and R. P. Sharma. 1973. Persistence of tri-o-tolyl phosphate (TOTP) and metabolites in chicken tissues as related to neurotoxicity. Pesticides and The Environment. Interscience Medical Book Corp., pp. 503-512.

Watanabe, P. G. and R. P. Sharma. 1975. Neurotoxicity of organophosphates. J. Comp. Path. 85:373-381. 
Watanabe, P. G. and R. P. Sharma. 1976. Lymphatic tissue response in chickens treated with TOTP. J. Toxicol. Environ. Health $1: 777-786$.

Watanabe, P. G. and R. P. Sharma. 1977. TOTP neurotoxicity: Lack of evidence for autoimmunologic involvement. Arch. Environ. Contam. Toxicol. 6:233-240.

Wolfe, H. R., W. F. Durham, and J. F. Armstrong. 1967. Exposure of workers to pesticides. Arch. Environ. Health 14:622-633. 


\section{VITA}

Craig R. Brinkerhoff

Candidate for the Degree of

Master of Science

Thesis: The Effects of Tri-o-tolyl Phosphate on the Immune System of Mice

Major Field: Toxicology

Biographical Information:

Personal Data: Born at Kanab, Utah, December 9, 1953, son of S. Max and Annabelle R. Brinkerhoff.

Education: Attended elementary school in St. George, Utah; graduated from Dixie High School in St. George, Utah, 1972; received the Bachelor of Science degree from Utah State University with a major in Biology and a minor in Chemistry, June, 1978; completed the requirenents for the Master of Science degree specializing in Toxicology at Utah State University, 1980.

Professional Experience: Research Assistant, Veterinary Science Department, Utah State University, 1979-1980. 